\title{
Resumen antológico de la obra métrica de Pedro Henríquez Ureña
}

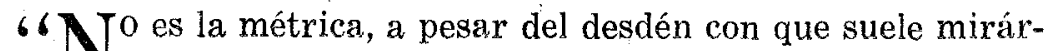

- sela desde la época romántica, como parte de la destronada Retórica, asunto baladí o estudio vacío, propio tan solo de la erudición indigesta: es porción esencial y efectiva de la técnica literaria, a la cual consagraron sabio esmero los Griegos y los Latinos, y conocimiento necesario para integrar la filosofía de la composición, según lo mostró Hegel en elocuente páginas de su Estética". 1 A esta porción esencial y efectiva de la técnica literaria Pedro Henríquez Ureña ha consagrado varios estudios de suma importancia en la historia literaria - estudios de verdadera erudición y genuina intuición estética. Se ha propuesto descubrir los elementos fundamentales de la métrica española y obrando sin vendar los ojos con viejos prejuicios y sin más teoría que la del valor de la rigurosa observación científica, ha ido examinando los versos de poeta y plebe no sólo de los países de habla española sino de otros muchos antiguos y modernos - unas veces en busca de la historia de un verso particular, de una estrofa, o de un sistema, otras veces en busca del verso puro. Guiado sólo por su deseo de conocer a fondo el verdadero ritmo de la poesía española, ha logrado descubrir hechos históricos y verdades poéticas antes insospechadas. Aunque se puede dividir la obra métrica de Henríquez Ureña en tres partes principales ${ }^{2}$-la

1 Pedro Henriquez Ureña, "El verso endecasilabo", en Horas de estudio, París, 1910, p. 138.

2 Ha estudiado vatios problemas de métrica: Rubén Datio, 1905 (publi- 
que trata del endecasílabo castellano $0^{3}$ (en que distingue cinco tipos de endecasílabo castellano en vez de los dos tipos generalmente definidos por los tratadistas anteriores), la de investigaciones sobre la versificación irregular española ${ }^{4}$, y la del estudio del verso puro ${ }^{5}$ se puede decir de toda ella lo que ha dicho Menéndez Pidal de La versificación irregular en la

cado también en Horas de estudio, París, 1910, 113-137); Don Juan Ruiz de Alarcón, México, Nosotros, 1914: "La métrica de los poetas mexicanos en la época de la Independencia", Boletin de la Sociedad Mexicana de Geografía y Estadistica, 1914, 19-28; "Notas sobre Pedro Espinosa", Revista de Filologia Española, IV, 1917, 289-292; "Rubén Dario y el siglo xv", Revue Hispanique, L, 1920, 324-327; "El modelo estrófico de los 'layes, decires y canciones' de Rubén Darío", Revista de Filología Española, XIX, 1932, 421-422; "La versificación de Heredia", Revista de Filologia Hispánica, IV, 1942, 171-172; "Los jueces de Castilla", ibid., VI, 1944, 285-286; "La cuaderna via", ibid., VII, 1945, 45-47; "Sobre la historia del alejandrino", ibid., VIII, 1946, 1-11. Quisiera añadir aquí una nota importante sobre el arte mayor citada de una carta que me escribió Pedro Henríquez Ureña en 1941: "No creo que en estos casos haya cesura: 'Cuando las áncoras quis levantar'; precisamente me parece que la cesura ha sido deliberadamente suprimida y que hay enjambement entre el primer hemistiquio y el segundo."

3 "Cuestiones métricas. El verso endecasilabo", Revista Moderina de México, XII, 1909, 27-40 (también en Horas de estudio, París, 1910, pp. 138-147); "El endecasílabo castellano", Revista de Filología Española, VI, 1919, 132-157; "El endecasílabo castellano", Boletín de la Academia Argentina de Letras, XIII, 1944, 725-824. En "Rubén Dario" (p. 123) dice: "Con su última radical innovación, este gran revolucionario ataca precisamente el óptimo tesoro de nuestra métrica: el endecasílabo... Si en el Pórtico no mezcló este endecasílabo con el yámbico, en otras composiciones, no sólo los mezcla, sino que liberta completamente el ritmo de nuestro verso heroico..."

4 Antología de la versificación ritmica, San José de Costa Rica, 1918 (con prólogo de Alfonso Reyes); Antología de la versificación vítmica, México, Cultura, X, 1919; "El apogeo de la versificación irregular. 1600-1675", Nosotros, XXXIII, 1919, 445-451 (parte del capítulo IV del libro La versif. irreg. ...); "La versificación irregular en la poesía castellana", Caba Contemporánea, XXII, $1920,372-386$ (introducción y capítulo I del libro del mismo título); La versificación irregular en la poesía castellana, Madrid, 1920 (segunda edición, 1933); "Problemas del verso español", Cursos y Conferencias, 1935, no 5; "Problemas del verso español. La versificación fluctuante en la poesía de la Edad Media (11001400), Cursos y Conferencias, IX, 1936, 491-505.

5 "En busca del verso puro", Valoraciones, IV, 1926-1927, pp. 3-6, 73-88, 174-177 (teproducido en Cursos y Conferencias, IV, 1934, 225-249, y en Homenaje a Enrique José Varona en el cincuentenario de su primer curso de filosofía (18801930), La Habana, 1935, 29-48). 
poesía castellana: "Y bien puede decirse que Henríquez Ureña, penetrando la esencia musical de esta métrica antes desconocida, abriendo el espíritu del lector a gustar bellezas que antes dejaban insensibles a la crítica, ha conquistado una nueva provincia para la historia literaria".

Sería ocioso elogiar más la obra que ha destruido la superstición del isosilabismo, cambiando profundamente el concepto de la métrica española, la obra que ha hecho no sólo aceptable sino obligatoria la libre investigación de problemas métricos españoles. Ya son casi axiomáticas las ideas de Henríquez Ureña sobre la fluctuación en la versificación española -ideas que serían escandalosas en los primeros años del siglo veinte, ideas que nos hacen comprender claramente la raison d'être del verso libre moderno. Tan bien conocida, en efecto, es La versificación irregular en la poesía castellana, obra repetidamente citada por los especialistas, que sobran comentarios. No será superfluo, sin embargo, subrayar una vez más la importancia del verso irregular en la métrica española. La importancia de la fluctuación métrica es evidente si se considera la historia del verso irregular, historia que me propongo trazar brevemente ofreciendo al lector el siguiente pastiche de la obra maestra de nuestro autor:

"Desde el siglo XII hasta fines deI XIV, el fenómeno de la fluctuación existe, salvo excepciones bien contadas, en toda la versificación española, pero con caracteres diversos y en grados distintos. Es general, eso sí: la irregularidad métrica estaba en todas partes, en el ambiente, y no sólo en los asendereados copistas (p. 34). El isosilabismo se erige en norma de la versificación castellana, pero no en norma absoluta: el principio de la versificación acentual, con grandes libertades respecto de las sílabas, se impone precisamente cuando las formas amétricas desaparecen (hacia 1400) (p. 37). Durante doscientos años, desde que puede comprobarse su existencia en la literatura castellana, la versificación irregular de tipo acentual, o con vaga tendencia acentual, imperfectamente definida, sale a la superficie pocas veces: pero a fines del siglo XV sube a gozar de prestigio y sigue disfrutándolo desde en-

6. Segunda edición, p. VI. Todas las citas son de esta edición. 
tonces: primero entre el pueblo mucho más que entre los poetas cortesanos y ciudadanos; luego, difundiéndose por igual entre uno y otros (p. 97). Hasta 1600, la versificación acentual está comunmente en manos populares y vulgares, y recibe poca atención de los hombres de letras; desde 1600, los poetas cultos se apoderan de ella, y acaban por transformarla, regularizándola (p. 98). Al terminar el siglo XVI, los elementos populares, cuya ascensión hacia las letras cortesanas, desde la época de los Reyes Católicos, había sido gradual, pero constante, acaban por penetrar de lleno en el drama, en la poesía lírica, en la novela. Lope es el gran maestro de este movimiento en lo que atañe a la versificación, entre otras cosas. Coetáneos suyos, Cervantes, Góngora, los dramaturgos de Valencia, son quienes mejor contribuyen a la innovación. El carácter renacentista del siglo de Carlos $V$ va cediendo cada vez más ante el reflujo de tendencias nativas que dan su peculiar sabor al siglo XVII en España (p. 209). El apogeo de la versificación irregular en las manifestaciones cultas de las letras castellanas coincide con la época de mayor esplendor del teatro, a la vez del profano y del religioso. Se adaptaba a maravilla esa versificación a los episodios de canto y danza que formaron parte principal del espectáculo cuyo núcleo era la comedia y cuyos incidentes y accesorios, a veces excesivos en número, requerían a menudo el empleo de la música. La versificación irregular mantiene el contacto con la poesía del pueblo, sobre todo antes de 1650 ; pero los poetas la escriben libremente en ocasiones, ya sea tratando de imitar el estilo popular, como ocurre con Lope y Tirso, ya sea sin reminiscencia alguna de los orígenes, como ocurre con Calderón o con Castillo Solórzano. La versificación sigue girando dentro de sus círculos originarios: la seguidilla, el metro de gaita gallega, el metro donde predomina el eneasílabo. Durante poco tiempo, trata de definirse otro en que habría predominado el decasílabo bipartito. Fuera de esos, continúan los esquemas libres: los más de ellos, durante el siglo XVII, con predominio de las medidas largas (pp. 275-276). A partir de 1650, toda esta brillante variedad se irá regularizando y reduciendo. Las seguidillas y los versos de gaita gallega se volverán regulares, sometidos a las leyes del isosilabismo, como la silva de origen 
italiano; los otros esquemas desaparecerán al fin. La versificación irregular, después de prolongar su existencia en relativa oscuridad en el teatro cómico, desaparecerá de toda poesía culta y volverá al seno de las masas anónimas de donde habían subido hacia las cortes (p. 276). Hacia el final del siglo XVIII, la antigua versificación irregular ha desaparecido a tal punto de la literatura, que ni siquiera sus reliquias parecen peligrosas a los clasicistas académicos, y se comienzan a exhumar versos desusados, como el endecasílabo de gaita gallega o el eneasílabo o el dodecasílabo o el decasílabo bipartito, para emplearlos en combinaciones isosilábicas e isométricas (pp. 282-283). El isosilabismo no lo violaron nunca los románticos (apenas hubo uno que otro desliz de Espronceda, momentáneamente, cuando se enredaba en algún intento métrico extravagante), y sus ataques contra la isometría de las estrofas, audaces al principio, fueron reduciéndose gradualmente, hasta desvanecerse. De la irregularidad silábica sólo se salen, en rigor, unos pocos intentos de resucitar la cantidad grecolatina: los más interesantes son los de Juan Gualberto González. Este imperio de la uniformidad isosilábica durará hasta 1895, más o menos (p. 285). El libro que señala el resurgimiento de la versificación iregular en la literatura es Prosas profanas, de Rubén Darío, publicado en Buenos Aires en 1896. El movimiento, como se ve, principia en la literatura de América: es reflejo del movimiento en favor del moderno verso libre, que tiene su centro en Francia y de allí irradia a muchos países. Caracteriza al libro de Rubén Darío la gran variedad de metros, manejados todos con rara perfección, con exquisito sentido de sus cualidades musicales, sin repetir nunca demasiado ritmos iguales dentro de cada tipo de verso. El deseo de hacer de todos los metros conocidos en castellano instrumentos igualmente flexibles - deseo que nace con el siglo XIX- llega aquí a su realización, no lograda ni por los últimos clásicos académicos ni por los románticos ( $p .317$ ). La versificación plenamente irregular, amétrica, iniciada de modo tímido por Darío, continúa difundiéndose y adquiere brillo en los poemas de José Santos Chocano, del Perú, y en el Lunario sentimental (Buenos Aires, 1909), de Leopoldo Lugones, de la Argentina, antiguio jefe de la extrema izquierda en el movimiento que se 
llamó modernista (p. 329). En tiempos recientes, Juan Ramón Jiménez se convierte en el principal cultivador de los metros libres. En sus libros últimos, Diario de un poeta recién casado (Madrid, 1917), Eternidades (1918), Piedra y cielo (1919) : emplea constantemente la versificación irregular (pp. 331-332). Como se ve, el movimiento iniciado en América entre 1890 y 1895, y extendido a España desde 1900, ha restaurado en la poesía culta los dos tipos de versificación irregular que habían existido en castellano: el amétrico, que domina desde el siglo XII hasta el XIV, y el acentual, que florece del XIV al XVII. El tipo amétrico moderno, aunque unas veces coincida con el medieval en la tendencia a aproximarse a paradigmas isosilábicos, otras veces desecha toda aproximación a la regularidad y busca efectos singulares. Cerca de ellos se encuentran los ocasionales ensayos de prosa rítmica, la cual, por definición, debería distinguirse del verso, faltándole la unidad que debe caracterizarlo (p. 335)". Y una advertencia final: "Los dos extremos en que puede caer la versificación irregular son la prosa, el sonsonete de baile. El tipo amétrico, manejado por versificadores que no posean el sentido justo de la unidad rítmica que constituye el verso, puede llegar a no distinguirse de la prosa. El tipo acentual puede convertirse en sonsonete monótono, si el versificador no cuida de variar los efectos con la distribución de los golpes o altas, a la vez que el número de sílabas, como lo hacen los poetas de idiomas en que la poesía es meramente acentual, sin sujeción al número fijo de sílabas. De uno y otro extremos deberán huir los poetas de lengua castellana, si quieren mantener viva $\mathrm{y}$ eficaz la riqueza de versificación conquistada durante los últimos años (pp. 335-336)".

Ya se ve que el verso irregular, aunque irregular, es verso. Pese a quien pese, hay que admitirlo en la familia de los versos legítimos de la poesía. ¿Hasta dónde, entonces, puede llegar la irregularidad de un verso? ¿Hasta la prosa? ¿Cómo definir el verso -el verso puro? ¿Cómo distinguirlo de la prosa? "¿Será cierto que hay dos únicos modos de expresión verbal: el verso y la prosa? ¿Y será cierto que el verso y la prosa deben mantenerse puros, antitéticos e inconfundibles entre sí? Vivimos bajo el terror de que nos descubran paren- 
tesco con el inmortal bourgeois gentilhomme. Y más si el parentesco existe. Pero padecemos escrúpulos innecesarios. Quizás M. Jourdain era menos tonto de lo que Molière creía, como Bouvard y Pécuchet eran menos tontos de lo que Flaubert creyó. Quizás no era M. Jourdain quien se equivocaba, sino el maestro de retórica, según hábitos de su tribu. Recordemos al árabe describiendo la prédica de Mahoma: 'No es poesía, ni es prosa, ni es lenguaje mágico, pero impresiona, penetra...".?

En el artículo "En busca del verso puro", estudio no tan bien conocido como La versificación irregular de la poesía castellana, por ser casi inaccesible, pero esencial para los que desean comprender el verso libre, Henríquez Ureña examina las definiciones del verso de varias lenguas, antiguas como modernas, en busca de la definición mínima, la noción genérica, del verso. De este artículo he escogido los siguientes párrafos, florilegio que bien puede servir de abecedario en el estudio de la métrica:

"Para desvanecer el prejuicio de que sólo es verso el de nuestro idioma en nuestro tiempo, de que sólo merece el nombre aquella unidad rítmica cuyas leyes nos son familiares, nada mejor que una peregrinación a tierras lejanas. Los pueblos que nos son exóticos hablan lenguas cuyos sistemas gramaticales resultan irónicamente contrarios al nuestro; su música se organiza sobre escalas distintas de las nuestras. ¿No será natural que el verso difiera? Lo es.

"El verso varía de pueblo a pueblo, de siglo a siglo. Pero varía menos que las armazones lingüísticas o los sistemas tonales, porque trabaja con material uniforme, la sílaba, arcilla sonora sujeta a modulaciones pero intacta en su esencia.

"Si representamos con letras los recursos principales del verso, podremos resumir en fórmulas la versificación de todos los idiomas. Sean: A, la unidad fluctuante, de medida elástica; B, la combinación de versos desiguales; C, la cesura; D, el número fijo de sílabas; $\mathbf{E}$, la regulación de la cantidad, el número fijo de valores de sílabas (largas y breves) ; F, los

7 "En busca del verso puro", en Homenaje a Envique José Varona, p. 29. Todas las citas son de esta edición. 
acentos de intensidad; $\mathrm{G}$, la regulación de los tonos o diferencias de altura musical entre las sílabas; $\mathrm{H}$, la rima; $\mathrm{I}$, la aliteración; J, el encadenamiento; $\mathrm{K}$, el paralelismo; $\mathrm{L}$, el acróstico". (págs. 36-37).

"Desatando al verso de la cadena de rigores con que se pretende sujetarlo, todavía se aferra al último eslabón: la ley del ritmo. ¿Es justa, entonces, la familiar definición del verso como unidad rítmica?

"Sí: la definición es justa siempre que se encierre dentro del círculo exacto de definición mínima, siempre que se recoja estrechamente dentro de la noción limpia y elemental de ritmo, apartando de sí cualquier enredo con la idea de acento o de tono o de cantidad, cualquier exigencia de igualdades o siquiera de relaciones matemáticas". (p. 30).

"El verso, en su esencia invariable a través de todos los idiomas y de todos los tiempos, como grupo de fonemas, como "agrupación de sonidos", obedece sólo a una ley rítmica primaria: la de la repetición. Ritmo, en su fórmula elemental, es repetición. El verso, en sencillez pura, es unidad rítmica porque se repite y forma series: para formar series, las unidades pueden ser semejantes o desemejantes.

"La unidad aislada carece de valor: la serie le da carácter rítmico y la frecuencia del uso le presta apariencia de entidad. Cuando decimos que frases como 'Lo cierto por lo dudoso' o 'Amar sin saber a quién' o 'En un lugar de la Mancha' son versos octosílabos, es que la abundancia de aquel tipo métrico en la poesía española crea costumbre y obliga al oído a reconocerlo suelto o dentro de la prosa. Cualquier tipo de versificación, cuando es nuevo, cuando falta la costumbre de él, desconcierta al oyente: los tradicionalistas sentencian que 'no es verso', que 'suena mal al oído'. Así se dijo del endecasílabo español en el siglo XVI; así, a fines del XIX, de la rica versificación de Rubén Darío y los suyos; todavía se oyen ecos de aquella disputa cuando estalla otra nueva..." (p. 31).

"La excursión a través de unas cuantas literaturas de Asia, Africa y Europa revela cuántos fenómenos distintos reciben el nombre de verso. ¿Qué habrá de común entre el Hai Kai de los japoneses, cuyo único recurso rítmico es la regularidad aritmética de la serie de sílabas, y el poema germánico, 
con sus incisivos acentos, pausas y aliteraciones, pero de medida silábica vaga? ¿Qué habrá de común entre la estrofa de Safo o de Anacreonte, tejida con delicados filamentos de matices en la duración del sonido y la profecía hebraica, en versículos de extensión indeterminada, unidos por la duplicación o el contraste de los pensamientos o las imágenes? ¿Qué habrá de común entre las rigurosas runas finlandesas del Kalevala, todas de ocho sílabas, con cuatro acentos fijos, con aliteración y paralelismo, y los vagos contornos del cantarcillo español, ceñidos apenas por el lazo pueril del asonante? De común sólo existe la noción mínima, esencial, de unidad rítmica (la fórmula $\mathrm{A}$ ).

"A la unidad rítmica, desnuda y clara, se atiene el verso libre a que se consagran hoy, en típica confluencia, poetas jóvenes de las más divergentes naciones occidentales. Si es verdad que nuestro tiempo cava hasta llegar a la semilla de las cosas para echarlas a que germinen de nuevo y crezcan libres; si el empeño de simplificación y de claridad toca a los fundamentos de los valores espirituales, y del valor económico, y de la actividad política, y de la vida familiar ¿por qué no ha de tocar a las formas de expresión? Reducido a su esencia pura, sin apoyos rítmicos accesorios, el verso conserva intacto su poder de expresar, su razón de existir. Los apoyos rítmicos, que a unos les parecen necesarios, a otros les sobran o les estorban. $Y$ tales apoyos tienen vida limitada: recorren ciclos y desaparecen. Desapareció la cantidad en los viejos idiomas indoeuropeos; desapareció la aliteración en los germánicos ... El siglo XIX, en Europa, está lleno de quejas contra la rima. ¿Por qué la rima resiste todavía el ataque? Cuando se la expulsa, se va con ella el cuento de sílabas: de otro modo, habríamos creado especies nuevas de verso blanco en medidas exactas... No hay formas universales ni eternas". (pp. 4345).

\section{¿NO HAY FORMAS UNIVERSALES NI ETERNAS!}

"Aceptemos la sobriedad máxima del ritmo: el verso puro, la unidad fluctuante, está ensayando vida autónoma. No acepta 
apoyos rítmicos exteriores; se contenta con el impulso íntimo de su vuelo espiritual". (p. 45).

El problema de definir la poesía - significación espiritual- queda intacto después de definir el verso, fenómeno del orden de los sonidos. Si al verso alcanzamos a encerrarlo dentro del círculo de la noción mínima, es porque existe como entidad sonora en todas las lenguas, $y$, despojado de sus variaciones, persiste como unidad rítmica que se desarrolla en series. Pero queda el otro problema adyacente, el de los límites entre la prosa y el verso. $\mathrm{Y}$ este problema, que muchos pretenden resolver con el tajo brusco entre las dos formas, sólo admite una solución: la separación entre el verso y la prosa no es absoluta; del verso a la prosa hay grados, escalones, etapas descendentes.

"Se dice, con la solemnidad del maestro de M. Jourdain, que hablamos en prosa. Distingo. Hay dos acepciones de prosa, una negativa y otra positiva. Si — según al arbitrio populardecidimos aplicar el nombre de prosa a cualquier uso del lenguaje que no sea verso, podrá tolerársele su explicación al retórico de la comedia. Pero si el nombre se aplica a una forma de expresión literaria, obra de esfuerzo consciente y claro propósito, no hablamos en prosa. Hablamos, y nada más.

"La historia no deja dudas: la prosa no nace como mera proyección del lenguaje hablado; se crea como derivación y a ejemplo del verso". (págs. 45-46).

Digamos, en conclusión, contrahaciendo una predicción que hizo Henríquez Ureña de la obra de Rubén Darío: las historias futuras consagrarán a Henríquez Ureña como el Sumo Intérprete de la versificación castellana: si no el que mejor ha interpretado ciertos metros típicos de la lengua, sí el que mayor variedad de metros ha descubierto.

\section{DoRothy Clotelle ClaRke. Universidad de California, Berkeley.}

